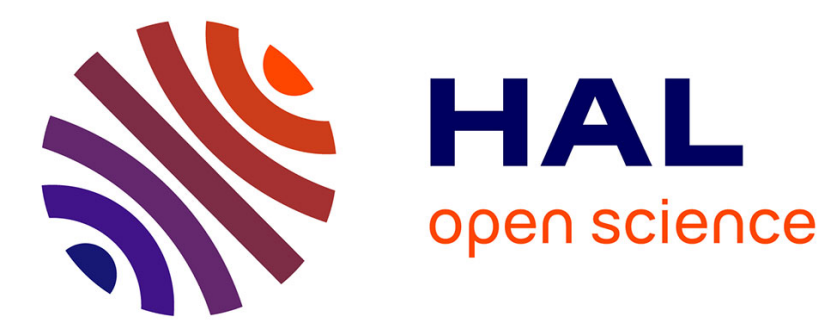

\title{
How Product Development Can Be Improved in Fast Fashion Industry: An Italian Case
}

\author{
Elisa D'avolio, Romeo Bandinelli, Rinaldo Rinaldi
}

\section{To cite this version:}

Elisa D'avolio, Romeo Bandinelli, Rinaldo Rinaldi. How Product Development Can Be Improved in Fast Fashion Industry: An Italian Case. 12th IFIP International Conference on Product Lifecycle Management (PLM), Oct 2015, Doha, Qatar. pp.718-728, 10.1007/978-3-319-33111-9_65 . hal01377499

\section{HAL Id: hal-01377499 \\ https://inria.hal.science/hal-01377499}

Submitted on 7 Oct 2016

HAL is a multi-disciplinary open access archive for the deposit and dissemination of scientific research documents, whether they are published or not. The documents may come from teaching and research institutions in France or abroad, or from public or private research centers.
L'archive ouverte pluridisciplinaire HAL, est destinée au dépôt et à la diffusion de documents scientifiques de niveau recherche, publiés ou non, émanant des établissements d'enseignement et de recherche français ou étrangers, des laboratoires publics ou privés. 


\title{
How Product Development can be improved in Fast Fashion industry: an Italian case
}

\author{
Elisa d‘Avolio, Romeo Bandinelli, Rinaldo Rinaldi, \\ Department of Industrial Engineering, University of Florence, Florence, Italy \\ elisa.davolio@unifi.it \\ romeo.bandinelli@unifi.it \\ rinaldo.rinaldi@unifi.it
}

\begin{abstract}
The fast fashion industry is characterized by a complex supply chain configuration, lots of players and an important critical success factor: time to market. In order to ensure the compliance to the fashion collection timing, the entire Product Development process has to be optimized through the analysis of both the flows of material and information. The authors have personally been involved in an in-depth case study, aiming to investigate the earlier phase of a PLM implementation and trying to merge business processes with proper enabling information technologies. The present study strives for analyzing the underexplored topic of improving Product Development in the fashion industry as well as identifying best practices for business process re-engineering in the industrial environment.
\end{abstract}

Keywords: Process re-engineering; Product Lifecycle Management; PLM; Fashion industry; Product Development.

\section{Introduction}

\subsection{Improving Product Development in the fashion industry}

Today's fashion business demands a high degree of collaboration and global business skill. Fashion companies need to be agile, sensitive to changing customer needs, constantly monitoring customer buying behavior and delivering high quality products.

The economic pressures bearing on fashion companies come from both ends of the value chain, consumers and retailers expect lower and lower prices, while the costs of sourcing, manufacturing, and delivering have to be constantly monitored.

Fast fashion industry, in particular, is characterized by trends that change rapidly and consumers across the world expecting to choose the latest product. Consequently, fast fashion companies need to speed up their processes: this is the reason why timing is a challenging issue in this environment. 
Strategies based on low product cost and traditional business practices are no longer sustainable. Product Development ask for innovative solutions supporting design, purchasing and costing in order to maintain its competitive advantage.

Managing a large repository of information involving stakeholders from different parts of the world brings down the operational efficiency of the company.

Fast fashion companies are trying to integrate the various teams on a common platform to take care of all these inefficiencies. The implementation of Product Lifecycle Management (PLM) allows successful integration across the fashion enterprise: it is not just a technology, but a strategic business approach that integrates people, processes, business systems and information.

PLM also requires a strategic transformation initiative: before its implementation, companies need to spend significant time developing plans to address people, processes and data.

The link between people/processes/data and PLM is represented by a business process mapping, which aims to identify the most critical tasks and the main nonvalue added processes. The identification and modelling of enterprise processes can be used as an efficient tool to capture and share process knowledge within the organization [1] and to give more visibility to the roles involved in each activity.

When fashion companies realize that business process need to be re-engineered, they should establish a change leadership team that includes executives and business process leaders with a deep commitment. Their role is to coach and influence middlemanagers and business function leads, focus their change efforts and to provide a forum for objective discussions of gaps, progress and lessons learned. They also provide executive-sponsored support for continuous process optimization and issue resolution.

The topic of Product Development improvement in the fashion industry has been underexplored for many years, because it is originally related to handcrafted traditions and introducing standardization in the kingdom of creativity appears an ambitious objective.

Nowadays fashion companies have recognized the importance of optimize their core processes and ask for innovative solutions to manage complexity.

\subsection{Background for research}

Before approaching to the core part of the research, a literature review has been conducted in order to recognize the depth of the studies about product development improvement and their proximity to the fashion industry.

The product typology, its high creative content, its very short lifecycle and the related processes generate a distance from the manufacturing industry but several concepts, as definitions of Business Process Re-engineering (BPR) and PLM, are more generalizable.

According to Bertoni et al. [2], since the design and development of a new PLM solution require an adequate analysis of the involved business processes, it is often coupled with a BPR activity to better deploy technologies and/or methodologies . 
Huang and Mak [3] have defined BPR as a transformation approach that allow to rationalize the product development process, resulting in better product design decisions.

BPR aims at simplifying, eliminating and redesigning business processes for greater efficiency and cost reduction [4]. It is able to determine where and how to improve the processes and it is adopted in different industries to map all the activities throughout the entire value chain [5]. It is a knowledge intensive activity which requires a strong interoperation between all its participants.

Schuh et al. [1] have proposed a process oriented PLM framework where the identification of models encompassing business practices plays an important role.

Other approaches to the earlier phase of the PLM implementation have been presented by Messaadia et al. [6], through the deployment of systems engineering processes to model PLM requirements, and by Ristova and Gecevska [7] and Zhang et al. [8], proposing the Analytical Hierarchy Process methodology as a tool to support decisions regarding investment in PLM.

The leitmotiv in these studies is that they are related to the manufacturing industry and none of the cited studies analyzes the fashion industry. The same phenomenon is replicated in the topics of PLM general description and its implementation: the most part of the studies ([9],[10], [11], [12], [12], [13]) is focused on the manufacturing industry.

BPR, PLM and the need to improve product development are practices actually spread also in the fashion industry. This study has the purpose to fill the gap between the implementation of business practices supporting product development in the fashion industry and the lack of related literature.

The authors would like to underline how handcrafted processes can be merged with outstanding innovative practices and to demonstrate that standardization, whatever form it takes, leads to conformity, but does not stifle creativity.

Therefore, the goal of the present study is to analyze the earlier phase of a PLM implementation project, highlighting the main optimization areas for the analyzed industry.

The remainder of this paper is structured as follows. The second section describes the approach adopted to achieve the research objective, including a depiction of the business case and the methodology implemented. In the third section, the project outcomes are analysed, detailing the deliverables of each phase throughout the case study. A discussion of the main results has been provided in the fourth section and finally, the paper concludes with several remarks and future challenges.

\section{Research approach}

Enhancing product development through the best practices adopted in the fashion industry and taking advantage from the opportunities offered by the evolution of information technologies require project organization and proper methods.

An in depth case study has been performed with an exploratory purpose [14], given the early stage of this study. Multiple data sources were adopted, such as interviews, 
electronic and printed documents, group meetings with company employees [15] and existing IT solutions in order to understand the process flow, the types of data exchanged and to identify possible issues.

Indeed, case study research is especially appropriate for exploratory research, with a focus on documenting a phenomenon within its organizational context, exploring the boundaries of a phenomenon and integrating information from multiple sources [16]. The research has a longitudinal nature (January - March 2015) that has allowed the authors to observe and formulate organizational change.

The project was performed in a peculiar environment: while design and modeling are conducted in house, the purchase department is in contact with international strategic suppliers. It allows for insights into a wide range of organizational and technological issues.

Twenty-four interviews were conducted during the case study, varying between one to three hours each. The 24 interviewees were selected basing on a previous analysis of the Organizational Breakdown Structure (OBS): modelers, product responsible and graphic designers are divided per brand, line and gender; while buyers are divided per suppliers' geographical area. Marketing and Production officers have been included in the interviews for their impact on Product Development. Three meetings have involved also the ICT team, in order to have a comprehensive idea of the solutions implemented.

Before presenting the deliverables to the top management, the map of the As Is processes has been shared with the managers of product, modeling/prototyping, purchase and ICT departments. This early validation has ensured a fine-tuning of the process model.

After the As Is final validation, the project focused on underlining issues and future opportunities: a presentation has been designed to summarize these points and the methodology used. Proposals have been examined by the top management, that has given a feedback to finalize the To Be model. The project team has finally requested a validation of the To Be model and proposed a plan to select the PLM solution that better fits the business requirements.

In the figure below a timeline of the project is represented to better define the described steps.

A synthesis activity was undertaken in order to compare the project findings with the existing literature and the present study has been designed.

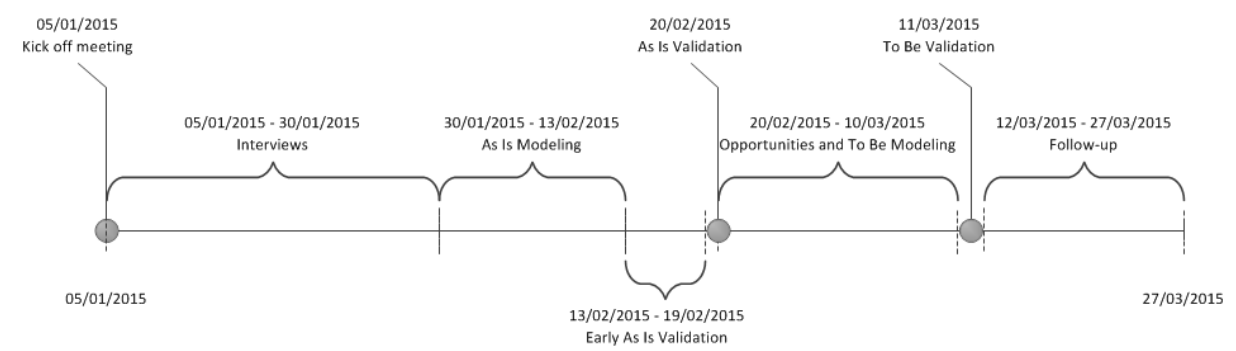

Figure 1 - Project timeline for the improvement of product development process 


\section{$3 \quad$ Project outcomes}

This section describes the main findings of the project, analyzing the current state of processes and technologies, the impact of the leading issues and the opportunities proposed. The final paragraph of this section is a development of the project, still on going.

\subsection{The current state analysis}

Business process modeling has allowed to map the entire set of tasks, milestones and data (hard copy and soft copy), including also the Business Unit (BU) involved and the specific roles. A model of the main macro-processes has been designed in Figure 2 and then, for each macro-process, tasks and information exchanged have been detailed.

Product managers and top management own the first macro-process, the collection briefing: sell-in and sell-out reports support the choice of the product categories (e.g. jackets, jumpsuits, pants...) that will characterize the collection. A spreadsheet recaps final price, target cost and margin for each product category. Moreover, the collection plan identifies the business milestones per product line (babies, kids, teens) that all the people involved in product development have to respect.

Concurrently, the Stylist and the Fashion Designer look for new trends and moods. This scouting activity is finalized by product managers, identifying the definitive collection mood.

The next macro process is mood development: style and product development define color libraries, fabrics, all-over, embroideries and artworks. The most part of the documents are physical or hard copies.

Since the fabrics are defined, the purchase office begins the macro process of preliminary quotation. Production areas are identified and the work load is distributed among the suppliers. The business asks for a sample and, if it is approved, asks also a preliminary quotation that will sustain the fabric booking.

The sampling process begins when the operations office starts to codify new fabrics and colors in the existing PDM and, together with the product development, advance the sample BOM. The purchase office books colored fabrics and accessories to the suppliers and product development progress technical draws and sketches for sampling. Modelers are now able to create patterns, prototypes and mock-up, using a 2D CAD solution. During this process, the model is simply developed in the base size. All the information required to finalize the sample production (BOMs, prototypes, patterns, comments) are collected within the Technical Dossier, which is sent to the supplier by the purchase office.

Product managers and buyers begin a series of fitting sessions during preview meetings and, when they approve a small set of sample, they ask the supplier to produce the entire set of samples. The orders are managed by the IT Team thanks the ERP solution, from this point to the production process.

During collection validation, Product managers and Modelers receive sample products and continue the fitting sessions, that now involve also selling agents. In the 
meanwhile, the collection book is created and updated after each fitting session. The exhibition date represents the milestone of this process: it is the final approval of the collection, when the sale network meets the business before the bulk production. The IT Team provides the final sample BOM approval and clones it to create the production BOM.

Concurrently, purchase and product development offices manage costing and engineering. Buyers finalize the standard costs negotiation, simulate and confirm a final cost, which will be integrated within the BOM. Product engineering is now completed.

The sales campaign starts when the sale network examines the collection and begins to order for the stores. Product managers collect orders and progress the sales campaign, producing also reporting data, as forecasts and competitors analyses that will be proposed to the top management.

The purchase office checks the compliance to the supplier requirements (minimum order) and issues a purchase order.

The final process within the boundaries of the project is production. Product managers update the new version of the BOM, that is the production BOM, and buyers ask for a pre-production sample. Modelers provide patterns changes, size grading and production fitting. Product coordinator traces the changes reached during the fitting sessions, from sampling to production, using a spreadsheet.

The product development office approves the final artworks and prepares the Technical Dossier, that the buyer will send to the supplier. The purchase office provides a timing for each supplier, defines priorities and sends the instruction notes for packaging. Before starting production, a meeting is scheduled at the supplier's factory to recap the bulk production quantity and timing. Buyers are in charge to control the production progress and produce reports (spreadsheets). When the supplier accomplishes the bulk production, he ships the order to the company. 


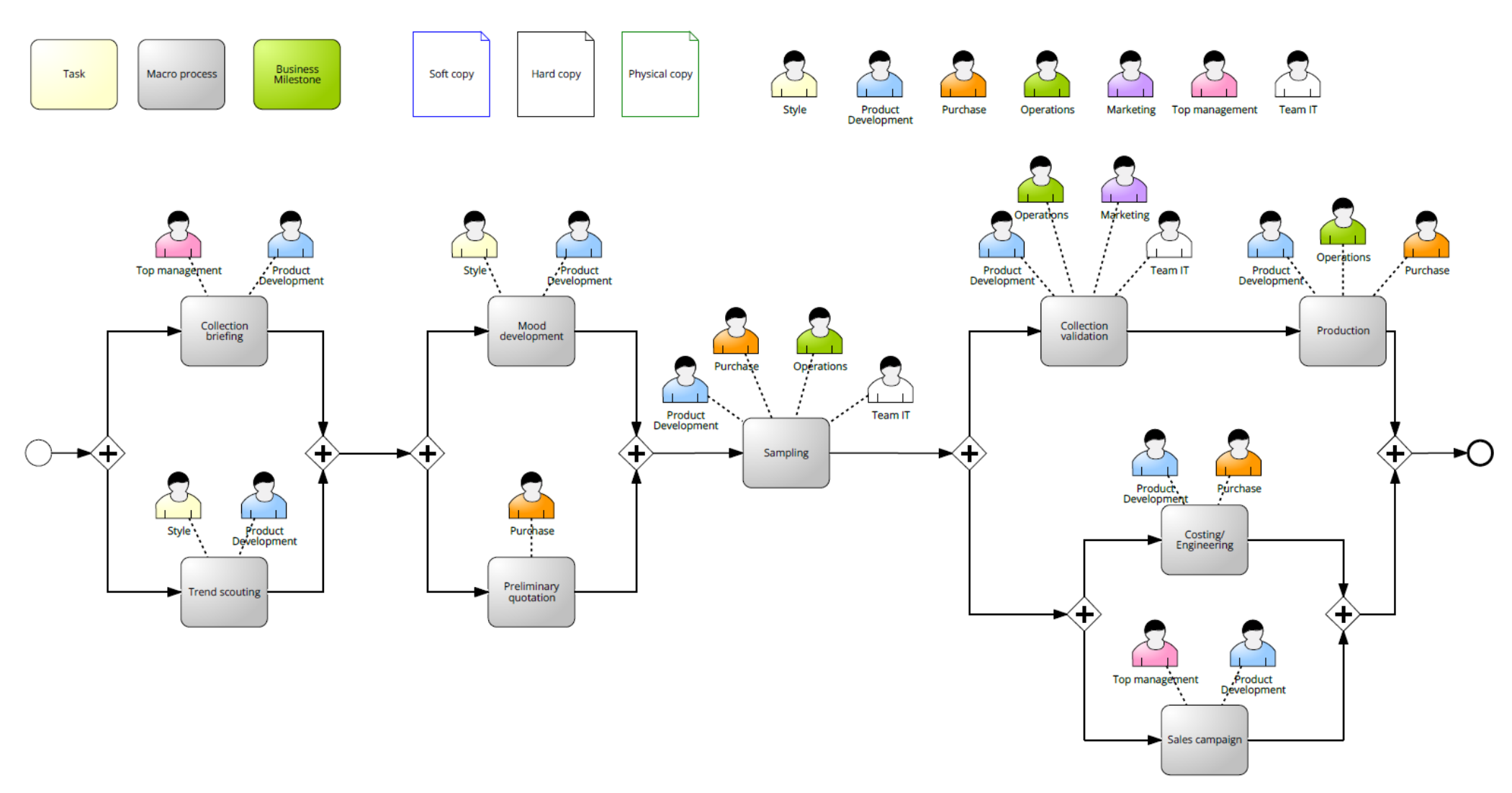

Figure 2 - As Is Business Process Model 
The implemented tools and the information generated during the macro-processes have been mapped in Figure 3.

FF Company uses different ICT supporting product development. When the top management establishes the boundaries of the collection, a business plan is performed: it is stored in a business repository.

A specific creative suite is able to produce sketch, draws and artworks. It receive inputs from the trends scouting: during this process a repository of the collection mood is generated, supported by the retail feedbacks. The creative suite is also used during the collection validation process, when creating the collection books.

A 2D CAD is employed to model paper patterns, prototypes and mock up. Moreover, all the size specifications are generated within CAD.

The information originated in the creative suite, as sketches, and the ones originated in $\mathrm{CAD}$, as size charts, consumptions and fitting notes, are inputs for the PDM, which receives also the information about collection planning. PDM is used to progress the main business milestones and, particularly, to associate technical data to the products, as sample and production BOM.

The production $\mathrm{BOM}$, in its approved state, is sent to the ERP which provides a definitive code for the product. Within ERP, sourcing, quotation information and purchase orders are managed.

When the BOM is completed and the product is progressed to the production process, product development office defines the composition. The latter is sent to a proper labeling solution, which generates labels for garments.

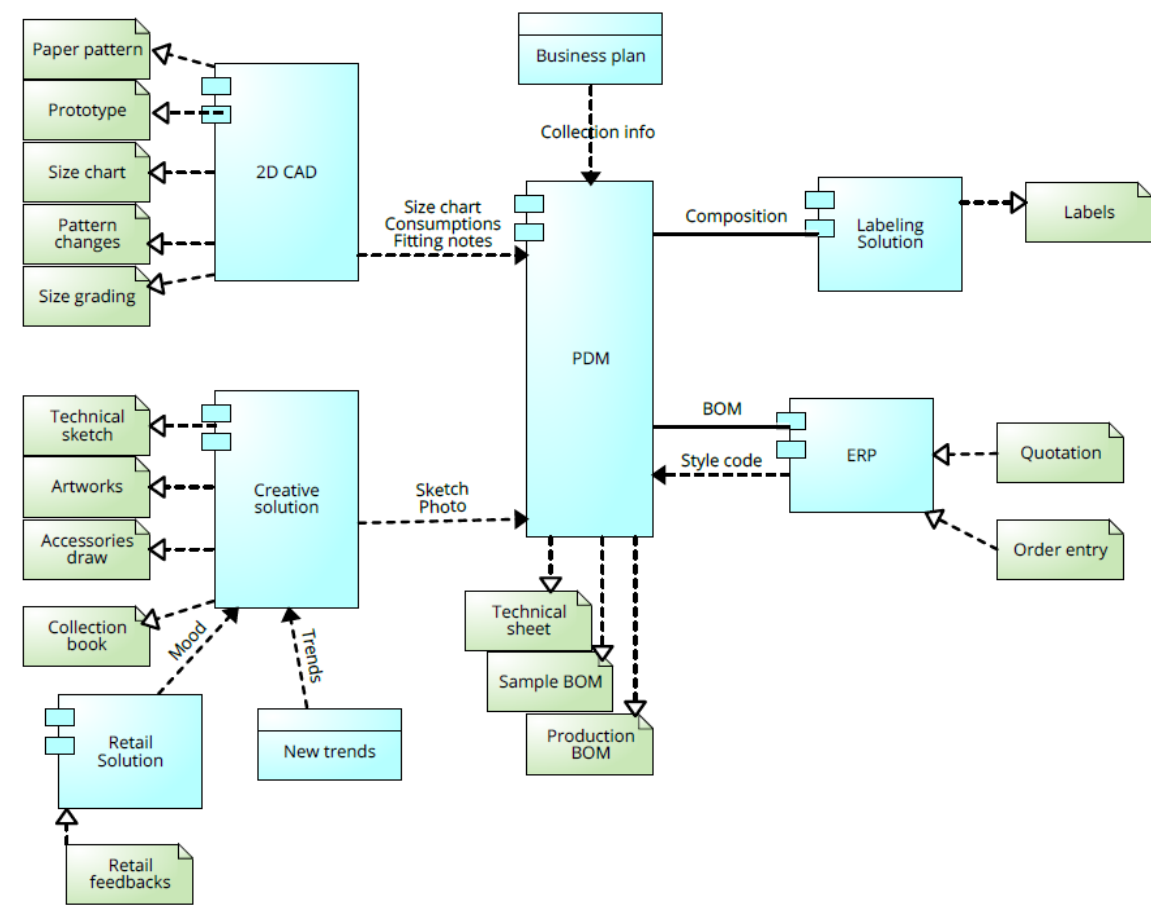

Figure 3 - As Is Enterprise Architecture Diagram 


\subsection{Issues, opportunities and To Be modeling}

The process analysis has not highlighted particular issues in the flow of activities, but the way these activities are managed is relevant because often no enterprise system is involved. Consequently, inefficiencies were reported, as re-entering data in spreadsheets, lack of univocal information and issues in promptly sharing updates and changes.

Each detailed process imploded in Figure 2 has been replicated, adding notes and comments and removing non value added tasks.

The company faces process issues due to the presence of many BUs, lots of brand and lines, lots of information in hard copy. Moreover, all the people involved in business value creation have consolidated several practices, fitting with specific needs, and consequently lots of similar reports are produced in different BUs.

On the other hand, IT architecture model has shown a lack of systems integration (a solution is isolated in a single business area), many spreadsheets and lack of versioning.

The scope of this section is to propose interventions to improve the Product Development process; the Discussion section will deepen the issues of this particular case study.

First of all, the functionalities of the PDM solution should be extended to the upstream activities concerning the Product Development process. For instance, collection briefing and business plan could be managed within a PDM/PLM solution.

Moreover, the functionalities related to collection planning and monitoring should be improved: a complete set of milestones could be identified and managed within PDM/PLM, avoiding to integrate information with spreadsheets.

Tasks and data in charge of the Style office, as fabric booking information, that are currently stored on directories, could be managed through a PDM/PLM solution.

FF Company uses in a proper way the PDM solution: it is the tool to share all the enterprise information and includes the overall technical data about sampling and production (except for costing).

Nevertheless, two main directions of improvement have been identified:

- Extension of the PDM functionalities

- Implementation of a new PLM solution

The first enhancement allows reusing the current system with its customizations and has a low impact on the users, who are already skilled on the tool functionalities.

On the other hand, the current PDM solution is in phase out and will need massive interventions to improve its adoption, without covering the entire set of functional requirements if compared to more up-to-date solutions.

The second enhancement proposed could satisfy all the functional and process requirements and constitutes a valuable state-of-the-art solution. The main drawbacks when introducing a new tool as PLM, are related to the huge investment required (for licences and customizations) and to the criticalities in training key users on a new technology. 


\subsection{Follow-up}

In this last phase of the case study, a finalization of the intervention proposals has been performed.

The first goal has been to identify a short list of PLM solutions supporting and fitting the needs of FF Company. The main vendors of industry-specific tools have been identified and contacted. A questionnaire, including information related to the main vendor's references, have been administered so that a benchmarking between the solutions has been provided.

Concurrently, we have asked the PDM vendor to perform a demo of the upgraded version of their solution and costs have also been evaluated.

Then, the costs and the return on investment of the entire PLM project have been estimated.

Finally FF Company got the inputs to decide how to concretely improve its Product Development process through appropriate ICTs.

\section{Discussion}

The in-depth case study has allowed a wider understanding of the optimization areas for fast fashion business processes and of the challenges that a company playing in this market has to face.

As a leader of children's wear, one important issue for FF Company is the size range, varying from 0 to 13 years. The apparel industry has in and of itself the characteristic to be critical in terms of fitting and size development. Moreover, managing apparel for children adds several issues for modelers, who have to be skilled to develop sizes for newborns and children, with very different fitting requirements. Consequently, lots of time is spent in modeling and engineering a single article and lots of fitting sessions are essential. Plotters, cutting machines and 2D CAD are useful tools to support this complex process.

There are too many paper based activities (i.e. materials tests and lab dips, fitting notes for samples and production, etc...), so it is more and more difficult to share documents and communicate in a timely manner to suppliers, trading companies, sales agents, distribution channels. Therefore, data digitization may solve several issues.

The costing activity is poor within the design phase. In particular, planning and tracking of actual vs. target costs for each product and of collection costs, are overlooked.

The abuse of spreadsheets and shared directories characterizes this case study: sketches and silhouettes are stored in shared directories, with consequent issues in managing versioning and retrieving data. Moreover, enterprise systems are updated later, mostly to feed the ERP. Each department collects and processes data in local systems and the consequence is that there are diverging versions of the same data.

Many activities (briefing, line planning, style, books and catalogs) are not managed by enterprise systems. Moreover, due the existing spreadsheet-based reporting 
systems, each office needs to retrieve and elaborate several times the same information to produce customized reports, statistics, and line sheets.

These qualitative findings contribute to an empirical experience from a PLM preimplementation phase, including the industry-specific features of fast fashion for children's wear.

\section{Conclusions and future work}

This paper aims at identifying best practices for business process re-engineering in the fast fashion industry and at analyzing the earlier phase of a PLM implementation project, underlining the optimization areas.

The fashion industry is a complex environment, characterized by a huge importance of timing, so streamlining product development is crucial.

First of all, a literature review has demonstrated a lack of studies focused on business process re-engineering in the fashion industry. Thus, in order to reach the above mentioned goal, an in depth case study has been performed. It has involved a company leader of children's wear and allowed the authors to shed some light on product development features in terms of processes and information management.

Authors have strengthened their investigation through interviews, information and data analyses related to each single task.

The current state of business process model and enterprise architecture diagram has been designed and then validated by process owners and top management. Several issues, mainly related to information management, have been identified and two main directions to improve product development were proposed: an extension of PDM functionalities and the implementation of a new PLM solution.

In the follow-up phase of the project, the authors supported the business to finalize the intervention proposals, considering both benefits and costs related to the alternatives.

The existing ICTs appear to be not integrated and poor in terms of workflow and versioning management. Spreadsheets, hard copies and shared directories are currently used instead of appropriate tools supporting product development.

This study demonstrates that the complex dynamics related to the fashion industry need the help of innovation and IT solutions. Fashion companies are willing to improve their traditional processes and to merge handcrafted activities with enabling technologies.

The research also constitutes an insightful academic study that deepens the underexplored topic of improving product development in the fashion industry. This is one of the most value added feature of the research, trying to fill the gap between the implementation of business practices supporting product development in the considered industry and the lack of related literature.

The continuation of the case study, including the methodologies used for the software selection and the description of the PLM implementation project, may constitute a future research direction. 
In the future, more companies could be involved in order to increase the generalizability of the results. Moreover, a comparison with the luxury fashion industry could be performed to analyze the different behaviors.

\section{References}

1. Schuh, G., Rozenfeld, H., Assmus, D., Zancul, E.: Process oriented framework to suort PLM implementation. Computers in Industry 59, 210-218, (2008).

2. Bertoni, M., Bordegoni, M., Cugini, U., Regazzoni, D., Rizzi, C.: PLM paradigm: How to lead BPR within the Product Development field. Computers in Industry, 476-484, (2009).

3. Huang, G.Q. and Mak, K.L.: Re-engineering the product development process with "design for X". Proceedings of The Institution Of Mechanical Engineers, Part B: Journal Of Engineering Manufacture, v. 212 n. 4, 259-268, (1998).

4. Soliman, F.: Optimum level of process maing and least cost business process reengineering. International Journal of Operations \& Production Management, Vol. 18 Iss 9/10, $810-816,(1998)$.

5. Dale, B.G., Elkjaer, M.B.F., van der Wiele, A., Williams, A.R.T.: Fad, fashion and fit: an examination of quality circles, business process re-engineering and statistical process control. Interantional Journal of Production Economics 137-152, (2001).

6. Messaadia, M., El-Jamal, M.H., Sahraoui, A.: Systems Engineering processes deployment for PLM. International Conference on Product Life Cycle Management, Lyon, France, (2005).

7. Ristova, E. and Gecevska, V.: AHP methodology and selection of an advanced information technology due to PLM software adoption. XV International Scientific Conference on Industrial Systems, Novi Sad, Serbia, (2011).

8. Zhang, H., Ouzrout, Y., Bouras, A., Della Selva, V., Savino, M.M.: Selection of Product Lifecycle Management components based on AHP Methodologies. IEEE Xplore, 523 528, (2013).

9. Ameri, F. and Dutta, D.: Product Lifecycle Management: Closing the Knowledge Loops. Computer-Aided Design \& Alications, Vol. 2, No. 5, 577-590, (2005).

10. Le Duigou, J., Bernard, A., Perry, N. and Delplace, J.-C.: Generic PLM system for SMEs: Alication to an equipment manufacturer. International Journal of Product Lifecycle Management, Vol. 6, No. 1, 51-64, (2012).

11. Hans, C., Hribernik, K. A. and Thoben, K.-D.: Improving Reverse Logistics Processes Using Item-level Product Lifecycle Management. International Journal of Product Lifecycle Management, Vol. 4, No. 4, 338-359, (2010).

12. Terzi, S., Bouras, A., Dutta, D., Garetti, M. and Kiritsis, D.: Product lifecycle management - from its history to its new role. International Journal of Product Lifecycle Management, Vol. 4, No. 4, 360-389, (2010).

13. Bandinelli, R., Rinaldi, R., Rossi, M., Terzi, S., (2013), "New product development in the fashion industry: An empirical investigation of Italian firms", International Journal of Engineering Business Management, Vol.5, Special Issue Innovations in Fashion Industry.

14. Voss, C., Tsikriktsis, N., and Frohlich, M.: Case research in operations management. International Journal of Operations \& Production Management, Vol. 22 No. 2, 195-219, (2002).

15. Bokinge, M. and Malmqvist, J.: PLM implementation guidelines - relevance and application in practice: a discussion of findings from a retrospective case study. International Journal of Product Lifecycle Management, Vol. 6, No. 1, 79-98, (2012).

16. McDermott, C.M.: Managing radical product development in large manufacturing firms: a longitudinal study. Journal of Operations Management 17. 631-644, (1999). 